\title{
Use of neuroimaging to guide the treatment of patients beyond the 8-hour time window
}

Nazli Janjua, MD

Correspondence \& reprint requests to Dr. Janjua: nazli.janjua@apcsi.org

\section{ABSTRACT}

Revascularization time windows for patients with acute ischemic stroke are generally restricted to 8 hours. Later treatment attempts require more accurate prediction of risk and benefit, as safety and efficacy at these time strata are less well demonstrated. Advanced imaging techniques identify irreversible infarction as well as tissue at risk. Diffusion-weighted MRI detects ischemia within minutes of onset, whereas perfusion-weighted MRI and CT perfusion studies disclose the ischemic penumbra. Combined, they provide information on mismatched tissuepotentially salvageable brain. In addition, noninvasive angiography is a useful adjunct to localize arterial occlusion. Neurology ${ }^{\circledR}$ 2012;79 (Suppl 1):S95-S99

\section{GLOSSARY}

AIS $=$ acute ischemic stroke; ASPECTS $=$ Alberta Stroke Program Early CT Score; $\mathbf{C B F}=$ cerebral blood flow; $\mathbf{C B V}=$ cerebral blood volume; $\mathbf{C D M}$ = clinical-diffusion mismatch; $\mathbf{C T P}=$ CT perfusion; DEDAS = Dose Escalation of Desmoteplase in Acute Stroke; DEFUSE = Diffusion-Weighted Imaging Evaluation For Understanding Stroke Evolution Trial; DIAS II = Desmoteplase in Acute Ischemic Stroke Trial; DW-MRI = diffusion-weighted MRI; EPITHET = Echoplanar Imaging Thrombolytic Evaluation Trial; IA = intra-arterial; MR RESCUE = MR and Recanalization of Stroke Clots Using Embolectomy; $\mathbf{M T T}=$ mean transit time; $\mathbf{N I H S S}=$ $\mathrm{NIH}$ Stroke Scale; PDM = perfusion-diffusion mismatch; PWI = perfusion-weighted imaging; RESTORE = Reperfusion Therapy in Acute Ischemic Stroke with Unclear Onset by MRI Evaluation.

Approximately $25 \%$ of patients with acute ischemic stroke (AIS) first notice their deficit after a period of sleep (so-called wake-up strokes). ${ }^{1-3}$ The onset of symptoms is not precisely known, often extending beyond 8 hours. Though the time frames for endovascular treatments themselves are not standardized, these and other late-presenting patients are generally considered outside the typical maximum time periods of 6 hours for intra-arterial (IA) thrombolysis ${ }^{4-6}$ and 8 hours for mechanical thrombectomy. ${ }^{7-11}$ These treatment options, as with the case of systemic thrombolysis offered up to 4.5 hours from symptom onset, ${ }^{12,13}$ are based on screening with cranial noncontrast CT, known to be insensitive to early ischemia, potentially missing $60 \%$ of cases. ${ }^{14}$ The past decade has seen tremendous interest in the use of alternate imaging modalities such as MRI, particularly diffusion-weighted MRI (DW-MRI), which has a sensitivity for AIS of $94 \%$ in the ultra-early period, ${ }^{14}$ to refine triage for AIS therapy. DW-MRI serves as the basis for selection of patients for systemic thrombolysis at time windows up to 9 hours in a number of trials. ${ }^{15-18}$

PURPOSES OF IMAGING IN AIS PATIENTS BEYOND 8 HOURS: PREDICTING SAFETY AND BENEFIT Whereas trials of hyperacute therapy have established accepted rates of safety with use of only CT for patient selection, ${ }^{5,12,13}$ the paucity of population studies at later time strata creates a greater need for patient-specific information. This information must illustrate physiologic evidence of tissue viability, nonviability, and vulnerability. Among patients presenting within 8 hours of stroke, the primary purpose of cranial imaging is to rule out the presence of hemorrhage or widespread ischemia, which contraindicate revascularization efforts. In addition, though, recanalization may not necessarily lead to improved outcome; demonstration of arterial occlusion or hypoperfusion at least identifies a therapeutic target, thereby inferring therapeutic gain. This remains important for the post-8-hours patient and may even become more important because with increasing time windows, potential risk increases while possible benefit diminishes. This can be summarized as follows: with extended times of presentation, triage criteria must include highly sensitive assessment of both potential risk and benefit.

From Asia Pacific Comprehensive Stroke Institute, Pahoa, HI

Go to Neurology.org for full disclosures. Disclosures deemed relevant by the author, if any, are provided at the end of this article. 
Assessment of risk: CT vs MRI in detecting ischemia within 12 hours. The volume of pretreatment brain infarction correlates with subsequent hemorrhagic transformation after reperfusion. Baseline imaging must well define this territory. ${ }^{19}$ Correlative studies demonstrate that at time lengths of 12 hours from symptom onset, the sensitivity of CT approaches that of MRI. ${ }^{14}$ Given its ready availability, CT still has a role in the rapid assessment of patients presenting with new neurologic disturbance. It can, in effect, screen out those who a priori present with welldemarcated large-volume ischemic changes, who are at increased risk of hemorrhage. However, when there are questions about symptom onset time and extent of ischemia, such as in patients with wake-up strokes, plain head CT may be inadequate to guide treatment decisions. More accurate imaging tools to evaluate the precise size and stage of cerebral infarction are required, such as with DW-MRI, ${ }^{20}$ which plays an essential role in the triage of patients for endovascular treatment of AIS at time windows beyond 8 hours. In patients demonstrating larger DWI areas of abnormality, triage away from revascularization therapy is likely. ${ }^{21}$

For patients unable to undergo MRI (e.g., those with cardiac pacemakers) or in instances of unavailability of MRI, advanced CT applications play a role, which have the additional advantage of expediency, and in certain studies these have been found to be equivalent to DW-MRI in estimating infarct when using low cerebral blood volume (CBV) areas as well as abnormal cerebral blood flow (CBF) areas combined. ${ }^{22,23}$ CT perfusion (CTP) has been validated against xenon $\mathrm{CT}$ and has been found to be a reliable measure of infarct core and ischemic area. ${ }^{24} \mathrm{CTP}$ evaluates a bolus of contrast through a specified area of brain to calculate CBV. With use of mathematical algorithms, CBF and mean transit time (MTT) of blood in a region can also be calculated. Comparison of CTP with the Alberta Stroke Program Early CT Score (ASPECTS) ${ }^{25}$ showed that the ASPECTS ratings on the venous phase correlated with $\mathrm{CBV}$ regions and those on the arterial phase with $\mathrm{CBF} .{ }^{26}$ Other parameters of nonviability of tissue with $\mathrm{CBV}$ thresholds $<2 \mathrm{~mL} / 100 \mathrm{~g}, \mathrm{CBF}<20 \mathrm{~mL} / 100 \mathrm{~g} / \mathrm{min}$, and MTT $>8$ seconds have been identified. ${ }^{22}$ However, just as differing values for optimal threshold levels have been identified at different laboratories, more widely applicable values still require further validation.

Identification of ischemic penumbra: demonstration of mismatch. Perfusion-diffusion mismatch. The use of DWI in conjunction with MRI perfusion-weighted imaging (PWI), the perfusion-diffusion mismatch (PDM), has been evaluated in trials of systemic thrombolysis to identify candidates for therapy at
3-6 hours. ${ }^{15,18}$ These studies have investigated the utility of PDM as an alternate triaging method. Using highly sensitive means of identifying the infarcted tissue (DWI) and the area of cerebral hypoperfusion (PWI), this at once evaluates both possible risk as well as possible benefits of treatment. ${ }^{27,28}$ In the DiffusionWeighted Imaging Evaluation For Understanding Stroke Evolution (DEFUSE) Trial, malignant mismatch profiles (DWI lesions or PWI lesions $>100$ $\mathrm{mL}$, with transit time delay of 8 seconds or more in the affected territory) were associated with high rates of hemorrhage after thrombolysis, whereas patients demonstrating a target mismatch profile (DWI $<100$ $\mathrm{mL}$ and PWI $10 \mathrm{~mL} / 120 \%>$ DWI lesion volume) had higher rates of favorable outcome, with reperfusion (improvement of 8 points or more on the NIH Stroke Scale $[\mathrm{NIHSS}]^{29}$ score) occurring with thrombolysis. ${ }^{15}$ Though the initial results are promising, the single-arm design of the DEFUSE Trial (all patients treated with alteplase) limits further conclusions.

The randomized Echoplanar Imaging Thrombolysis Evaluation Trial (EPITHET) demonstrated that reperfusion was associated with improved neurologic outcome (decrease in NIHSS score by 8 or more points) and less infarct growth (decrease in the 3- to 5-day PWI volume, compared with baseline). The presence of PDM itself predicted increased reperfusion with alteplase. However, the primary endpoint of infarct growth was only nonsignificantly seen at a lower rate among alteplase-treated patients with mismatch. ${ }^{18}$

The reverse investigation, i.e., studying the effect of recanalization on perfusion imaging, is the subject of the ongoing MR and Recanalization of Stroke Clots Using Embolectomy (MR RESCUE) Trial, which may offer future insights into the physiology of the ischemic penumbra in the setting of changing arterial flow.

CTP-DWI or CTP-CT mismatch. As for PDM, CTP may also be used either in conjunction with DWI or with CTP source imaging data or noncontrast head CT to identify the area of ischemic penumbra beyond that of the infarcted core. ${ }^{26,30}$ Although CTP has the advantage over MRI of easier accessibility, the drawback is the volume of contrast required, which must be kept in mind when preparing for possible endovascular intervention and cumulative contrast dose. In addition, because abnormalities of perfusion are best appreciated by virtue of asymmetry with the opposite hemisphere, this technique is less optimal for posterior circulation pathology (although the same fallacy may also hold true for PWI).

Clinical-diffusion mismatch and other clinical-radiographic models. The ultimate assessment of benefit and proof of concept for endovascular therapy may be established on clinical grounds. Easily reproducible 
clinical measures, such as the NIHSS, ${ }^{29}$ may be compared to DWI appearance in demonstrating a so-called clinical-diffusion mismatch (CDM). ${ }^{31,32}$ Criteria including limited DWI areas of ischemia $(\leq 25 \mathrm{~mL}$ brain tissue) with moderate NIHSS scores (of at least 8) have been shown in prospective ${ }^{31}$ and retrospective $^{32}$ analyses to identify groups of AIS patients destined for infarct expansion and clinical deterioration in the subacute period. This has been studied retrospectively among patients presenting beyond 8 hours who have undergone endovascular therapy. ${ }^{33}$ An additional study applied the ASPECTS ${ }^{25}$ to brain DWI in nonlacunar anterior circulation infarction and also demonstrated a similar phenomenon of early neurologic deterioration and infarct expansion among patients with initial NIHSS score $\geq 8$ and ASPECTS $\geq 8 .{ }^{34}$

Comparison of CDM with PDM demonstrates decreased sensitivity with the CDM in identifying patients with greater viable yet vulnerable ischemic tissue, perhaps due to inadequacies of clinical scales, such as the NIHSS, to detect nondominant hemispheric lesions. PDM and CTP are thus perhaps of further value in identifying potential treatment candidates from among patients with stroke in the nondominant hemisphere.

Identification of large-vessel occlusion. The combination of vascular and brain imaging on MRI demonstrates the extent of infarction and presence of large-vessel occlusion. These MRA-DWI mismatches have identified patients who have better neurologic improvements with reperfusion therapy. ${ }^{35}$ Similarly, CTA has also been studied either in conjunction with noncontrast CT or DW-MRI, called a CTA-DWI or CTA-CT mismatch, to corroborate the same hypothesis. Evaluation of CTA source images can estimate nonviable tissue, although this awaits comparison with DW-MRI. If validated, this may be an expeditious means of establishing risk and benefit of endovascular reperfusion treatment in patients beyond standard time windows. CTA in comparison with MRA can be considered in triaging AIS patients for endovascular therapy, if medical comorbidities are not prohibitive of large contrast doses. ${ }^{36}$ Though the simple demonstration of arterial occlusion may not necessarily identify patients who will benefit (e.g., those with extended time windows of occlusion, such that salvageable tissue is lacking), the converse also has limitations, in that PWI or CTP models that identify ischemic tissue without identifying impaired collateral flow may underestimate tissue at risk. ${ }^{37}$
CURRENT STUDIES USING NEUROIMAGING TO GUIDE LATE TREATMENT AND FUTURE DIRECTIONS Several studies have used advanced imaging applications to guide the administration of systemic thrombolysis beyond the 3-hour window. The DEFUSE and EPITHET trials mentioned previously, as well as the Desmoteplase in Acute Ischemic Stroke (DIAS) and Dose Escalation of Desmoteplase in Acute Stroke (DEDAS) trials, utilize PDM to select patients for thrombolysis with a new-generation lytic agent between 3 and 9 hours. ${ }^{16,17}$ DIAS, though initially promising in its pilot phase, failed to show a benefit in subsequent studies. ${ }^{17}$ Ongoing phase III studies are further examining this. The sister trial, DEDAS, did show higher rates of favorable outcome and reperfusion among the high-dose desmoteplase group. ${ }^{16}$ Additional studies evaluating the safety of thrombolysis for wake-up stroke on the basis of MRI criteria have also been reported. ${ }^{38}$

A few preliminary trials using mismatch models to select patients for combined therapies (systemic thrombolysis as well as endovascular treatments) have been reported, including the results of the Reperfusion Therapy in Acute Ischemic Stroke with Unclear Onset by MRI Evaluation (RESTORE) Trial, presented at the 2011 International Stroke Conference, in Los Angeles. ${ }^{39}$ Other case series of imagingguided endovascular treatment beyond 8 hours have been published, ${ }^{40-42}$ including those studies serving as pilots for planned future clinical trials. ${ }^{33,41}$

DISCUSSION Effective radiologic screening for AIS patients beyond 8 hours requires accuracy to identify potential benefit and harm of treatment. With use of perfusion imaging parameters to identify areas of infarction and ischemia, time windows become less rigid and more patient-specific. DW-MRI provides reliable delineation of infarction. Penumbral and vascular imaging augments evaluation of potential treatment benefits. Future studies will make use of these imaging techniques in a variety of combinations to study possible benefit of endovascular intervention on select groups of patients presenting late.

\section{AUTHOR CONTRIBUTIONS}

Dr. Janjua: drafting/revising the manuscript, study concept or design.

\section{DISCLOSURE}

Dr. Janjua received funding for attendance at and participation in the Society of Vascular \& Interventional Neurology roundtable. Go to Neurology.org for full disclosures.

Received June 27, 2011. Accepted in final form September 13, 2011.

\section{REFERENCES}

1. Chaturvedi S, Adams HP Jr, Woolson RF. Circadian variation in ischemic stroke subtypes. Stroke 1999;30:17921795. 
2. Lago A, Geffner D, Tembl J, Landete L, Valero C, Baquero M. Circadian variation in acute ischemic stroke: a hospital-based study. Stroke 1998;29:1873-1875.

3. Elliot WJ. Cyclic and circadian variations in cardiovascular events. Am J Hypertens 2001;14:291S-295S.

4. del Zoppo GJ, Higashida RT, Furlan AJ, Pessin MS, Rowley HA, Gent M. PROACT: a phase II randomized trial of recombinant pro-urokinase by direct arterial delivery in acute middle cerebral artery stroke: PROACT investigators: Prolyse in Acute Cerebral Thromboembolism. Stroke 1998;29:4-11.

5. Furlan A, Higashida R, Wechsler L, et al. Intra-arterial prourokinase for acute ischemic stroke: the PROACT II Study: a randomized controlled trial: Prolyse in Acute Cerebral Thromboembolism. JAMA 1999;282:2003-2011.

6. Ogawa A, Mori E, Minematsu K, et al. Randomized trial of intraarterial infusion of urokinase within 6 hours of middle cerebral artery stroke: the Middle Cerebral Artery Embolism Local Fibrinolytic Intervention Trial (MELT), Japan. Stroke 2007;38:2633-2639.

7. Bose A, Henkes H, Alfke K, et al. The penumbra system: a mechanical device for the treatment of acute stroke due to thromboembolism. AJNR Am J Neuroradiol 2008;29: 1409-1413.

8. Gobin YP, Starkman S, Duckwiler GR, et al. MERCI 1: a phase 1 study of Mechanical Embolus Removal in Cerebral Ischemia. Stroke 2004;35:2848-2854.

9. Smith WS. Safety of mechanical thrombectomy and intravenous tissue plasminogen activator in acute ischemic stroke: results of the Multi Mechanical Embolus Removal in Cerebral Ischemia (MERCI) Trial, part I. AJNR Am J Neuroradiol 2006;27:1177-1182.

10. Smith WS, Sung G, Saver J, et al. Mechanical thrombectomy for acute ischemic stroke: final results of the Multi MERCI Trial. Stroke 2008;39:1205-1212.

11. Smith WS, Sung G, Starkman S, et al. Safety and efficacy of mechanical embolectomy in acute ischemic stroke: results of the MERCI Trial. Stroke 2005;36:1432-1438.

12. The National Institute of Neurological Disorders and Stroke rt-PA Stroke Study Group: tissue plasminogen activator for acute ischemic stroke. N Engl J Med 1995;333: 1581-1587.

13. Hacke W, Kaste M, Bluhmki E, et al. Thrombolysis with alteplase 3 to 4.5 hours after acute ischemic stroke. N Engl J Med 2008;359:1317-1329.

14. Mullins ME, Schaefer PW, Sorensen AG, et al. CT and conventional and diffusion-weighted MR imaging in acute stroke: study in 691 patients at presentation to the emergency department. Radiology 2002;224:353-360.

15. Albers GW, Thijs VN, Wechsler L, et al. Magnetic resonance imaging profiles predict clinical response to early reperfusion: the Diffusion and Perfusion Imaging Evaluation For Understanding Stroke Evolution (DEFUSE) Study. Ann Neurol 2006;60:508-517.

16. Furlan AJ, Eyding D, Albers GW, et al. Dose Escalation of Desmoteplase for Acute Ischemic Stroke (DEDAS): evidence of safety and efficacy 3 to 9 hours after stroke onset. Stroke 2006;37:1227-1231.

17. Hacke W, Furlan AJ, Al-Rawi Y, et al. Intravenous desmoteplase in patients with acute ischaemic stroke selected by MRI perfusion-diffusion weighted imaging or perfusion CT (DIAS-2): a prospective, randomised, doubleblind, placebo-controlled study. Lancet Neurol 2009;8: 141-150.
18. Davis SM, Donnan GA, Parsons MW, et al. Effects of alteplase beyond $3 \mathrm{~h}$ after stroke in the Echoplanar Imaging Thrombolytic Evaluation Trial (EPITHET): a placebo-controlled randomised trial. Lancet Neurol 2008; 7:299-309.

19. Hacke W, Kaste M, Fieschi C, et al. Intravenous thrombolysis with recombinant tissue plasminogen activator for acute hemispheric stroke: The European Cooperative Acute Stroke Study (ECASS). JAMA 1995;274:10171025.

20. Singer OC, Humpich MC, Fiehler J, et al. Risk for symptomatic intracerebral hemorrhage after thrombolysis assessed by diffusion-weighted magnetic resonance imaging. Ann Neurol 2008;63:52-60.

21. Lansberg MG, Thijs VN, Bammer R, et al. Risk factors of symptomatic intracerebral hemorrhage after tPA therapy for acute stroke. Stroke 2007;38:2275-2278.

22. Wintermark M, Flanders AE, Velthuis B, et al. Perfusion-CT assessment of infarct core and penumbra: receiver operating characteristic curve analysis in $130 \mathrm{pa}-$ tients suspected of acute hemispheric stroke. Stroke 2006; 37:979-985.

23. Wintermark M, Reichhart M, Cuisenaire O, et al. Comparison of admission perfusion computed tomography and qualitative diffusion- and perfusion-weighted magnetic resonance imaging in acute stroke patients. Stroke 2002; 33:2025-2031.

24. Wintermark M, Thiran JP, Maeder P, Schnyder P, Meuli R. Simultaneous measurement of regional cerebral blood flow by perfusion CT and stable xenon CT: a validation study. AJNR Am J Neuroradiol 2001;22:905-914.

25. Barber PA, Demchuk AM, Zhang J, Buchan AM. Validity and reliability of a quantitative computed tomography score in predicting outcome of hyperacute stroke before thrombolytic therapy: ASPECTS Study Group: Alberta Stroke Programme Early CT Score. Lancet 2000;355: $1670-1674$.

26. Wang XC, Gao PY, Xue J, Liu GR, Ma L. Identification of infarct core and penumbra in acute stroke using $\mathrm{CT}$ perfusion source images. AJNR Am J Neuroradiol 2009;31:34-39.

27. Marks MP, Olivot JM, Kemp S, et al. Patients with acute stroke treated with intravenous tPA 3-6 hours after stroke onset: correlations between MR angiography findings and perfusion- and diffusion-weighted imaging in the DEFUSE Study. Radiology 2008;249:614-623.

28. Olivot JM, Mlynash M, Thijs VN, et al. Relationships between infarct growth, clinical outcome, and early recanalization in Diffusion and Perfusion Imaging Evaluation For Understanding Stroke Evolution (DEFUSE). Stroke 2008;39:2257-2263.

29. Goldstein LB, Bertels C, Davis JN. Interrater reliability of the NIH Stroke Scale. Arch Neurol 1989;46:660-662.

30. Lin K, Do KG, Ong P, et al. Perfusion CT improves diagnostic accuracy for hyperacute ischemic stroke in the 3-hour window: study of 100 patients with diffusion MRI confirmation. Cerebrovasc Dis 2009;28:72-79.

31. Davalos A, Blanco M, Pedraza S, et al. The clinical-DWI mismatch: a new diagnostic approach to the brain tissue at risk of infarction. Neurology 2004;62:2187-2192.

32. Prosser J, Butcher K, Allport L, et al. Clinical-diffusion mismatch predicts the putative penumbra with high specificity. Stroke 2005;36:1700-1704. 
33. Janjua N, El-Gengahy A, Pile-Spellman J, Qureshi AI. Late endovascular revascularization in acute ischemic stroke based on clinical-diffusion mismatch. AJNR Am J Neuroradiol 2009:1024-1027.

34. Tei H, Uchiyama S, Usui T. Clinical-diffusion mismatch defined by NIHSS and aspects in non-lacunar anterior circulation infarction. J Neurol 2007;254:340-346.

35. Lansberg MG, Thijs VN, Bammer R, et al. The MRADWI mismatch identifies patients with stroke who are likely to benefit from reperfusion. Stroke 2008;39:2491-2496.

36. Schramm P, Schellinger PD, Fiebach JB, et al. Comparison of CT and CT angiography source images with diffusion-weighted imaging in patients with acute stroke within 6 hours after onset. Stroke 2002;33:2426-2432.

37. Schellinger PD, Chalela JA, Kang DW, Latour LL, Warach S. Diagnostic and prognostic value of early MR imaging vessel signs in hyperacute stroke patients imaged $<3$ hours and treated with recombinant tissue plasminogen activator. AJNR Am J Neuroradiol 2005;26:618624 .
38. Barreto AD, Martin-Schild S, Hallevi H, et al. Thrombolytic therapy for patients who wake-up with stroke. Stroke 2009;40:827-832.

39. Khang DW, Sohn SI, Yu KH, et al. Reperfusion Therapy in Acute Ischemic Stroke with Unclear Onset by MRI Evaluation (RESTORE). Presented at the International Stroke Conference; 2011; Los Angeles, CA.

40. Natarajan SK, Snyder KV, Siddiqui AH, Ionita CC, Hopkins LN, Levy EI. Safety and effectiveness of endovascular therapy after 8 hours of acute ischemic stroke onset and wake-up strokes. Stroke 2009;40:3269-3274.

41. Jovin TG, Liebeskind DS, Gupta R, et al. Imaging-based endovascular therapy for acute ischemic stroke due to proximal intracranial anterior circulation occlusion treated beyond 8 hours from time last seen well: retrospective multicenter analysis of 237 consecutive patients. Stroke 2011; 42:2206-2211.

42. Kuruvilla A, Norris GM, Xavier AR. Acute endovascular recanalization therapy in wake-up stroke. J Neurol Sci 2010;300:148-150. 


\section{Neurology}

\section{Use of neuroimaging to guide the treatment of patients beyond the 8-hour time window}

Nazli Janjua

Neurology 2012;79;S95-S99

DOI 10.1212/WNL.0b013e3182695826

This information is current as of September 24, 2012

\section{Updated Information \&} Services

References

Subspecialty Collections

Permissions \& Licensing

Reprints including high resolution figures, can be found at: http://n.neurology.org/content/79/13_Supplement_1/S95.full

This article cites 40 articles, 21 of which you can access for free at: http://n.neurology.org/content/79/13_Supplement_1/S95.full\#ref-list-1

This article, along with others on similar topics, appears in the following collection(s):

\section{All Cerebrovascular disease/Stroke}

http://n.neurology.org/cgi/collection/all_cerebrovascular_disease_strok e

DWI

http://n.neurology.org/cgi/collection/dwi

Embolism

http://n.neurology.org/cgi/collection/embolism

Infarction

http://n.neurology.org/cgi/collection/infarction

MRI

http://n.neurology.org/cgi/collection/mri

Information about reproducing this article in parts (figures,tables) or in its entirety can be found online at:

http://www.neurology.org/about/about_the_journal\#permissions

Information about ordering reprints can be found online:

http://n.neurology.org/subscribers/advertise

Neurology ${ }^{\circledR}$ is the official journal of the American Academy of Neurology. Published continuously since 1951, it is now a weekly with 48 issues per year. Copyright Copyright @ 2012 by AAN Enterprises, Inc.. All rights reserved. Print ISSN: 0028-3878. Online ISSN: 1526-632X.

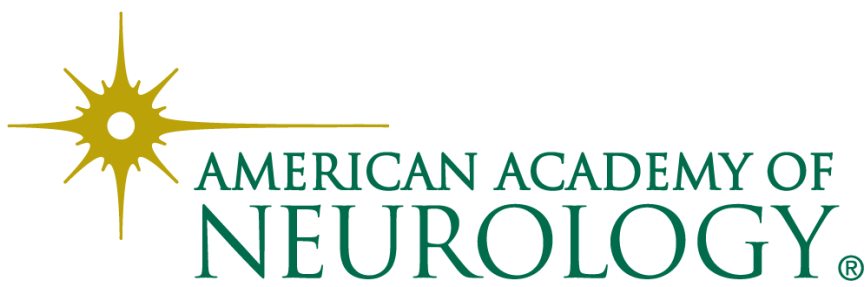

